\title{
The prospective protective effect of selenium nanoparticles against chromium-induced oxidative and cellular damage in rat thyroid
}

This article was published in the following Dove Press journal:

International Journal of Nanomedicine

30 April 2013

Number of times this article has been viewed

\author{
Kamel MA Hassanin' \\ Samraa H Abd El-Kawi \\ Khalid S Hashem' \\ 'Department of Biochemistry, Faculty \\ of Veterinary Medicine, ${ }^{2}$ Department \\ of Histology, Faculty of Medicine, \\ Beni-Suef University, Beni-Suef, Egypt
}

Background: Nanotechnology has enabled researchers to synthesize nanosize particles that possess increased surface areas. Compared to conventional microparticles, it has resulted in increased interactions with biological targets.

Objective: The objective of this study was to determine the protective ability of selenium nanoparticles against hexavalent chromium-induced thyrotoxicity.

Design: Twenty male rats were used in the study, and arbitrarily assigned to four groups. Group 1 was the control group, and was given phosphate-buffered saline. Group 2 was the chromium-treated group and was given $\mathrm{K}_{2} \mathrm{Cr}_{2} \mathrm{O}_{7} 60 \mu \mathrm{g} / \mathrm{kg}$ body weight intraperitoneally as a single dose on the third day of administration. Group 3 was the nano-selenium-treated group and was given selenium nanoparticles (size 3-20 nm) $0.5 \mathrm{mg} / \mathrm{kg}$ body weight intraperitoneally daily for 5 consecutive days. Group 4 was the nano-selenium chromium-treated group, which received selenium nanoparticles for 5 days and a single dose of $\mathrm{K}_{2} \mathrm{Cr}_{2} \mathrm{O}_{7}$ on the third day of administration.

Materials and methods: Blood samples were collected from rats for measuring thyroid hormones (free triiodothyronine $\left[\mathrm{T}_{3}\right]$ and free thyroxine $\left[\mathrm{T}_{4}\right]$ ) and oxidative and antioxidant parameters (malondialdehyde [MDA], reduced glutathione [GSH], catalase, and superoxide dismutase [SOD]). Upon dissection, thyroid glands were taken for histopathological examination by using paraffin preparations stained with hematoxylin and eosin (H\&E) and Masson's trichrome. Immunohistochemical staining was performed for detecting cellular proliferation using Ki67 antibodies.

Results: The present study shows that $\mathrm{K}_{2} \mathrm{Cr}_{2} \mathrm{O}_{7}$ has a toxic effect on the thyroid gland as a result of inducing a marked oxidative damage and release of reactive oxygen species. This was shown by the significant decrease in free $\mathrm{T}_{3}$ and $\mathrm{T}_{4}$ and GSH levels, which was accompanied by significant increases in catalase, SOD, and MDA in the chromium-treated group compared to the control group. Se nanoparticles have a protective effect on $\mathrm{K}_{2} \mathrm{Cr}_{2} \mathrm{O}_{7}$-induced thyroid damage, as a result of correcting the free $\mathrm{T}_{3}$ and $\mathrm{T}_{4}$ levels and GSH, catalase, SOD, and MDA compared to the $\mathrm{K}_{2} \mathrm{Cr}_{2} \mathrm{O}_{7}$-treated group. Administration of nano-selenium alone in the nano-selenium-treated group had no toxic effect on rats' thyroid compared to the control group. The biochemical results were confirmed by histopathological, immunohistochemical and pathomorphological studies.

Keywords: chromium, selenium nanoparticles, thyrotoxicity, protective effect

\section{Introduction}

Nanotechnology is the design and manipulation of materials on the atomic scale. The novel properties that emerge as materials, rated on the nanoscale, open the door to innovations in energy, manufacturing, and medical treatment. 
Recent years have witnessed an unprecedented growth in research in the area of nanoscience. There is increasing optimism that nanotechnology applied to medicine will bring significant advances in the diagnosis, treatment, and prevention of disease. Nanotechnology holds promise for medication and nutrition, because materials at the nanometer dimension exhibit novel properties different from those of both isolated atoms and bulk material. At the same time, these novel properties may pose new risks to workers, consumers, the public, and the environment. The limited data now available demonstrate the potential for some nanomaterials to be persistent and mobile in the environment and in living organisms, and to cross multiple physiologic barriers (including lung-blood, blood-brain, and placental barriers, as well as cell membranes).,

Selenium, from the Greek "selene" (meaning moon), is a chemical element (atomic number 34) that was discovered as a by-product of sulfuric acid. ${ }^{3}$ Fittingly, selenium was also detected in the moon dust brought back by the 1969 Apollo mission. ${ }^{4}$ Although, it was largely ignored as a therapeutic agent for over 100 years due to its toxicity, recent decades have confirmed its importance for mammalian life, with the recognition that selenium coordinates the functioning of certain proteins, designated as selenoproteins. ${ }^{5,6}$

Foods that are particularly rich in selenium are shellfish, crabs, kidney, liver, and Brazil nuts. Although diet is the main source of selenium intake, improvement of dietary intake depends on the characterization of selenium bioavailability from various food sources. ${ }^{7}$ The chief form of selenium in plants is selenate, which is directly translocated from the soil, and selenium-containing proteins in which selenomethionine (SeMet) and selenocysteine replace methionine and cysteine, respectively. ${ }^{8}$ The incorporation of SeMet into the body proteins by substitution of methionine is a unique property of SeMet, providing a means of selenium storage in tissues; this feature makes it particularly beneficial as a form of nutritional supplementation. ${ }^{9}$

Selenium supplementation shows promising potential for enhancing glutathione peroxidase (GPx) and other selenoprotein activity in various pathological thyroid conditions. The efficacy of selenium supply frequently depends on the bioavailability of the used compounds. SeMet possesses excellent bioavailability and lower toxicity, and therefore it is more applicable for long-term administration. ${ }^{10}$

Recently, the introduction of nanosize elemental selenium produced a highly effective molecular compound, and when compared with SeMet, it showed similar efficacy in increasing antioxidant GPx activity while displaying lower toxicity. ${ }^{11}$ Nano-selenium has potent effects on upregulation of GPx, and it yields more efficacious results in the induction of glutathione $S$-transferase over the short term, but it causes less oxidative stress. ${ }^{12}$

These selenium nanoparticles also show high biological activity and good absorptive ability due to the interaction between the nanoparticles and $-\mathrm{NH}_{2}, \mathrm{C}=\mathrm{O},{ }^{-} \mathrm{COO}$, and $-\mathrm{C}-\mathrm{N}-$ groups of proteins. ${ }^{13}$ Studies on the biological activities of selenium and its nanoforms revealed that hollow spherical nanoparticles of selenium have strong antioxidant properties. ${ }^{14}$ Similar studies declared that nano-selenium has the ability to act as an antioxidant with reduced risk of ordinary selenium toxicity. ${ }^{15}$

The size of nano-selenium plays an important role in its biological activity, as 5-200 nm nano Se can directly scavenge free radicals in vitro in a size-dependent fashion. ${ }^{12}$ Several methods, including $\gamma$-irradiation and laser ablation, have been applied to synthesize selenium nanoparticles, but the most widely used synthetic approach for preparing selenium nanoparticles is chemical reduction. ${ }^{16}$

Chromium is a fascinating and versatile metal discovered two centuries ago. It makes the emerald green and the ruby red. An essential trace nutrient, its biologic activity depends on its valence state. Metallic chromium (valence zero, $\mathrm{Cr}-0)$ is inert. Chromium III ( $\mathrm{Cr}[\mathrm{III}])$ is found in foodstuffs, may be of therapeutic value, and is used as a nutritional supplement because of its better bioavailability. $\mathrm{Cr}(\mathrm{VI})$ is the form found in welding, plating, and chemical industries. ${ }^{17} \mathrm{Cr}$ (VI)originates mostly from industrial use. ${ }^{18}$ $\mathrm{Cr}(\mathrm{VI})$ is used in more than 50 industries, ${ }^{19}$ including mining, production of stainless steel and chrome pigments, leather tanning and is used as anticorrosive in cooking systems and boilers. ${ }^{18}$

The presence of chromium in the effluents is hazardous for animals and human beings, and it is now very well established that hexavalent chromium (Cr[VI]) is highly toxic to life forms, due to dermatotoxic, carcinogenic, neurotoxic, nephrotoxic, genotoxic, and immunotoxic effects. ${ }^{20}$

Several systemic toxicities of $\mathrm{Cr}(\mathrm{VI})$ have been demonstrated in experimental animals in vivo and in vitro..$^{21,22}$ Occupational and environmental exposure to compounds containing $\mathrm{Cr}(\mathrm{VI})$ is known to cause multiorgan toxicity, such as renal damage, allergy and asthma, and cancer of the respiratory tract in humans. ${ }^{18}$ For those exposed to chromium industries (eg, during welding or plating), $\mathrm{Cr}(\mathrm{VI})$ 
is the valence form involved; it generally enters the body by inhalation or transdermally, and in a form that readily crosses cell membranes. ${ }^{20}$

The molecular mechanism by which $\mathrm{Cr}(\mathrm{VI})$ elicits biological responses, either toxic or adaptive, is unclear at present, but is hypothesized to be related to its reduction to $\mathrm{Cr}(\mathrm{III})$ in cells. $\mathrm{Cr}(\mathrm{V})$ and $\mathrm{Cr}(\mathrm{III})$ are derived from reduction of $\mathrm{Cr}(\mathrm{VI})$ from covalent interaction with DNA and protein. Moreover, reduction may accompany the production of reactive oxygen species (ROS), resulting in oxidative stress. ${ }^{23}$

The thyroid is an essential endocrine gland of animal bodies, and its secretions are metabolically pertinent. Little or almost nothing has been reported concerning the effects of $\mathrm{Cr}(\mathrm{VI})$ on thyroid gland structure or its secretions. ${ }^{24}$

In this study, the use of nanoparticle-based antioxidants as a potential treatment for thyrotoxicity was explored. One obvious use of nanoparticles would be for enhancing the performance of antioxidants. Therefore, the aim of this study was to design a rat model for thyrotoxicity and to determine the extent to which Se nanoparticles safeguard against chromium-induced thyrotoxicity in this model.

\section{Materials and methods Chemicals}

All chemicals used in this study were of analytical grade. Hexavalent Chromium (Cr[VI]) was purchased from El Gumhoria (Cairo, Egypt) in a synthetic-form potassium dichromate $\left(\mathrm{K}_{2} \mathrm{Cr}_{2} \mathrm{O}_{7}\right)$. Selenium nanoparticles $(3-20 \mathrm{~nm}$ particle size) were obtained from the Nanotechnology Unit, Faculty of Pharmacy, Beni-Suef University, Egypt, as a sterilized solution, as they were dispersed in phosphate-buffered saline (PBS) and ready for use. Ketamine and xylazine were obtained from Sigma-Aldrich, Gillingham, UK. Transmission electron microscopy was used for characterization of nanoparticles (shape and size) (Figure 1).

\section{Experimental animals}

This study was approved by the Committee of Scientific Ethics at Beni-Suef University, Egypt, and was carried out in accordance with its guidelines for animal use. Twenty male albino Wistar rats weighing on average 200-250 g were used in this study. They were obtained from the animal house of the Research Institute of Ophthalmology, Giza, Egypt. They were kept under suitable conditions for 1 week for adaptation. They were maintained in stainless steel cages in a wellventilated animal house at normal temperature $\left(22^{\circ} \mathrm{C} \pm 5^{\circ} \mathrm{C}\right)$

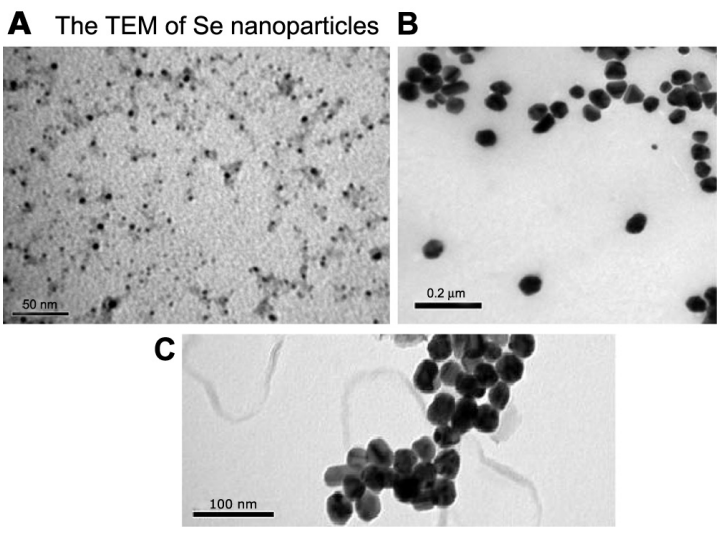

Figure I (A-C) Transmission electron microscopy of Se nanoparticles shows their shape and size at different magnification power.

Notes: The images reveal that Se nanoparticles are 3-20 $\mathrm{nm}$ and spherical. Se atoms are dispersed homogeneously in solution and not agglomerated. (A) Bar $50 \mathrm{~nm}$; (B) bar $0.2 \mu \mathrm{m}$; (C) bar $100 \mathrm{~nm}$.

under a 12:12-hour light-dark cycle. They were fed with standard diet and given water ad libitum. The rats were randomly divided into four equal groups (five rats each).

Group 1 (control) rats were given a single dose of sterile PBS (0.5 mL intraperitoneally [IP]) as a single dose. Group 2 (chromium-treated group) rats were given a single dose of $\mathrm{K}_{2} \mathrm{Cr}_{2} \mathrm{O}_{7}(60 \mu \mathrm{g} / \mathrm{kg}$ body weight dissolved in $0.5 \mathrm{~mL}$ PBS IP), ${ }^{24}$ on the third day of administration. Group 3 (nanoselenium-treated group) rats were given nano-selenium $(0.5 \mathrm{mg} / \mathrm{kg} \text { body weight dispersed in } 0.5 \mathrm{~mL} \text { PBS IP })^{12}$ daily for 5 consecutive days. Group 4 (nano-selenium chromiumtreated group) rats were given nano-selenium $(0.5 \mathrm{mg} / \mathrm{kg}$ body weight dispersed in $0.5 \mathrm{~mL}$ PBS IP) daily for 5 consecutive days and were also given a single dose of $\mathrm{K}_{2} \mathrm{Cr}_{2} \mathrm{O}_{7}$ ( $60 \mu \mathrm{g} / \mathrm{kg}$ body weight dissolved in $0.5 \mathrm{~mL}$ PBS IP) on the third day of administration.

Twenty-four hours after administration of the last dose, blood samples were taken from the medial canthus of the eyes of rats by capillary tubes into Wassermann tubes while they were under anesthesia. They were anesthetized with a 1.37:1 mixture of ketamine:xylazine $(1 \mathrm{~mL} / \mathrm{kg}$ body weight, IP). Blood samples were left at room temperature for 20 minutes to clot. They were centrifuged at $1000 \mathrm{~g}$ for 15 minutes to separate serum. Serum was stored at $-20^{\circ} \mathrm{C}$ till time of analysis. Thyroid glands were collected after dissection of $\mathrm{CO}_{2}$-killed rats.

\section{Methods \\ Biochemical studies}

The following parameters were measured in the serum of the four tested rat groups, according to the instructions 
of their referred methods: serum free triiodothyronine $\left(\mathrm{T}_{3}\right)$ and tetraiodothyronine $\left(\mathrm{T}_{4}\right)$ were measured by using Milliplex Map Rat Thyroid Hormone TSH Panel - 2 Plex (EMD Millipore, Billerica, MA, USA). Reduced glutathione (GSH), ${ }^{25}$ catalase, ${ }^{26}$ superoxide dismutase (SOD), ${ }^{27}$ and malondialdehyde (MDA), ${ }^{28,29}$ were measured in serum by using colorimetric assay kits (Biodiagnostic, Cairo, Egypt).

\section{Evaluating the size and the morphology of the selenium nanoparticles using transmission electron microscopy}

The size and morphology of the selenium was studied via the transmission of electron microscopy (JEOL, Tokyo, Japan). The microscope was operating at an accelerating voltage of $80 \mathrm{kV}$. The selenium samples were first diluted (1:10) in distilled water, and a $20 \mu \mathrm{L}$ aliquot was applied onto a carbon-coated grid. The solution was then left for 1 minute, and the excess was removed from the grid by blotting with a filter paper. The grids were placed in the grid box for 2 hours to dry before imaging.

\section{Statistical analysis}

All the biochemical and morphometric data were expressed as the mean \pm standard error. Differences between the means were tested by independent-sample $t$-tests for paired data. Statistical analysis was performed by using SPSS, version 16 (IBM, Armonk. NY, USA). A $P$-value less than 0.05 was considered significant.

\section{Light microscopic study}

To take thyroid tissues for histology, rats were anesthetized and killed. Thyroid tissues of all groups were immediately fixed in $10 \%$ neutral buffered formalin solution, and they were later processed for standard histological procedures. Thick paraffin-embedded sections $(5 \mu \mathrm{m})$ were stained with conventional H\&E, Masson's trichrome, and immunohistochemical stain by using Ki67: Monoclonal Mouse Anti-Human (Agilent Technologies, Santa Clara, CA, USA). This antibody was employed as the first antibody in the standard avidin-biotin immunoperoxidase complex method. ${ }^{30} \mathrm{~A}$ positive reaction was expressed as a relatively dark-brown color of the nucleus with a granular pattern, while a negative nucleus was not stained and appeared blue.

\section{Morphometric studies}

Thyroid gland morphometry was performed to determine the thyroid gland activity of control versus treated rats.
Morphometry data was collected by using a QWin 500 image analyzer (Leica Microsystems, Wetzlar, Germany). Twenty follicles for each animal were measured for cell height by selecting three epithelial cells at each of the 12, 5, and 7 o'clock positions and calculating their mean height. Optical density of Masson's trichrome was also measured in ten high-power fields by binary mode menu. Scoring of Ki67-immunostained nuclei - ten high-power fields (at magnification 400×) - were used to count the positive immunostained nuclei and to determine the Ki-67 labeling index. This index was defined as a percentage ratio of positively immunostained cells to the total number of counted cells.

\section{Results \\ Biochemical changes}

Measurement of the thyroid profile (free $\mathrm{T}_{3}$ and $\mathrm{T}_{4}$ ) in the serum of the four tested rat groups revealed that there was a significant decrease in free $\mathrm{T}_{3}$ and $\mathrm{T}_{4}$ levels $(P<0.01)$ in group 2 (chromium-treated group) compared with that of each of group 1 (control), group 3 (nano-selenium-treated group), and group 4 (nano-selenium chromium-treated group) (Table 1).

There was a significant decrease in the serum level of GSH in group 2 compared with that of each of groups 1, 3, and 4 . In contrast, measurement of the serum contents of MDA, catalase, and SOD showed a significant increase in their levels $(P<0.01)$ in group 2 compared with each of groups 1, 3, and 5 (Table 2).

\section{Histopathological changes}

Thyroid of saline-treated control rats (group 1) revealed variable-size follicles with normal interfollicular spaces and intact basal lamina (Figure 2A). Follicular epithelial cells were low-cuboidal to squamous. The colloid was normal and darkly stained in H\&E sections (Figure 2B) without noticeable retraction or desorption.

Thyroid tissues of group 2 rats showed hyperplasia of the intrafollicular epithelium, markedly visible follicular segregation, and increased interfollicular spaces (Figure 2C).

Table I Serum concentration of free triiodothyronine $\left(T_{3}\right)$ and free thyroxine $\left(T_{4}\right)$ in rats of the four tested groups

\begin{tabular}{lcc}
\hline Parameters & $\mathbf{T}_{3}(\mathbf{n g} / \mathbf{d L})$ & $\mathbf{T}_{4}(\mu \mathrm{g} / \mathbf{d L})$ \\
\hline Group I & $112.2 \pm 4.7$ & $9.3 \pm 0.69$ \\
Group 2 & $49.1 \pm 3.3^{*}$ & $5 \pm 0.39 *$ \\
Group 3 & $100.32 \pm 1.12$ & $8.4 \pm 0.9 \mathrm{I}$ \\
Group 4 & $91.7 \pm 3.9$ & $8.3 \pm 0.46$ \\
\hline
\end{tabular}

Notes: Values are expressed as means \pm standard error of mean. *Significant variation at $P<0.01$. 
Table 2 Oxidative and antioxidant parameters in serum of the rats in the four tested groups

\begin{tabular}{lcccc}
\hline & $\begin{array}{l}\text { GSH } \\
(\mathbf{m g} / \mathbf{d L})\end{array}$ & $\begin{array}{l}\text { MDA } \\
(\mathbf{n m o l} / \mathbf{m L})\end{array}$ & $\begin{array}{l}\text { Catalase } \\
(\mathbf{U} / \mathbf{m L})\end{array}$ & $\begin{array}{l}\text { SOD } \\
(\mathbf{U} / \mathbf{m L})\end{array}$ \\
\hline Group I & $66.2 \pm 7.1$ & $1.65 \pm 0.39$ & $3.1 \pm 0.38$ & $4.97 \pm 0.16$ \\
Group 2 & $40.5 \pm 1.5^{*}$ & $8.9 \pm 0.81^{*}$ & $6.9 \pm 0.46^{*}$ & $10.74 \pm 0.68^{*}$ \\
Group 3 & $60.32 \pm 1.2$ & $1.11 \pm 0.22$ & $2.98 \pm 0.21$ & $4.1 \pm 1.01$ \\
Group 4 & $71.5 \pm 5.2$ & $4.9 \pm 0.44$ & $3.9 \pm 0.42$ & $6.3 \pm 0.43$ \\
\hline
\end{tabular}

Note: *Significant variation at $P<0.01$.

Abbreviations: GSH, glutathione; MDA, malondialdehyde; SOD, superoxide dismutase.

Microscopic images also revealed desquamated irregularly shaped follicles with reduced colloidal space (Figure 2D and E). In group 3 rats, no histopathological changes were observed (Figure 2F).

In thyroid sections from rats of group 4, a markedly low level of cellular insult was found compared to group 2 rats. In these sections, follicles showed near-normal morphology (Figure 2G). Although epithelial cell nuclei appeared normal, congested blood capillaries were still encountered (Figure 2H).

In thyroids of control-group rats, collagen was minimally present within the gland (Figure $3 \mathrm{~A}$ ). In contrast, in thyroids of group 2 rats (Figure 3B), collagen deposition increased compared with those of the control-group rats, group 3 rats (Figure 3C), and group 4 rats (Figure 3D).

Regarding the immunohistochemical results, thyroids of rats of the control group exhibited weak proliferation, as shown by Ki67-positive nuclei (Figure 4A). However, in group 2, there was a positive nuclear immunostaining, as shown in Figure 4B, while in group 3 (Figure 4C) and group 4 (Figure 4D), nuclei showed weak positive nuclear immunostaining.

\section{Discussion}

In the past, several authors reported the absorption of the toxic heavy-metal chromium VI being absorbed by the animal body several times greater than $\mathrm{Cr}(\mathrm{III}) .{ }^{17} \mathrm{This}$ hexavalent chromium is proven to be toxic and carcinogenic. Its toxicity constitutes a major health hazard to the workers that are being exposed to this heavy metal in industrial areas. This hazard is not only restricted to workers but also it overreaches the general public residing in these industrial areas. Therefore, research trials have been carried out to study the protective role of some natural antioxidants, such as ascorbic acid, alpha tocopherol, and methionine, against heavy-metal toxicity. ${ }^{21}$ The present study showed hypofunction of thyroid gland and thyroid tissue insult following exposure to $\mathrm{Cr}(\mathrm{VI})$.
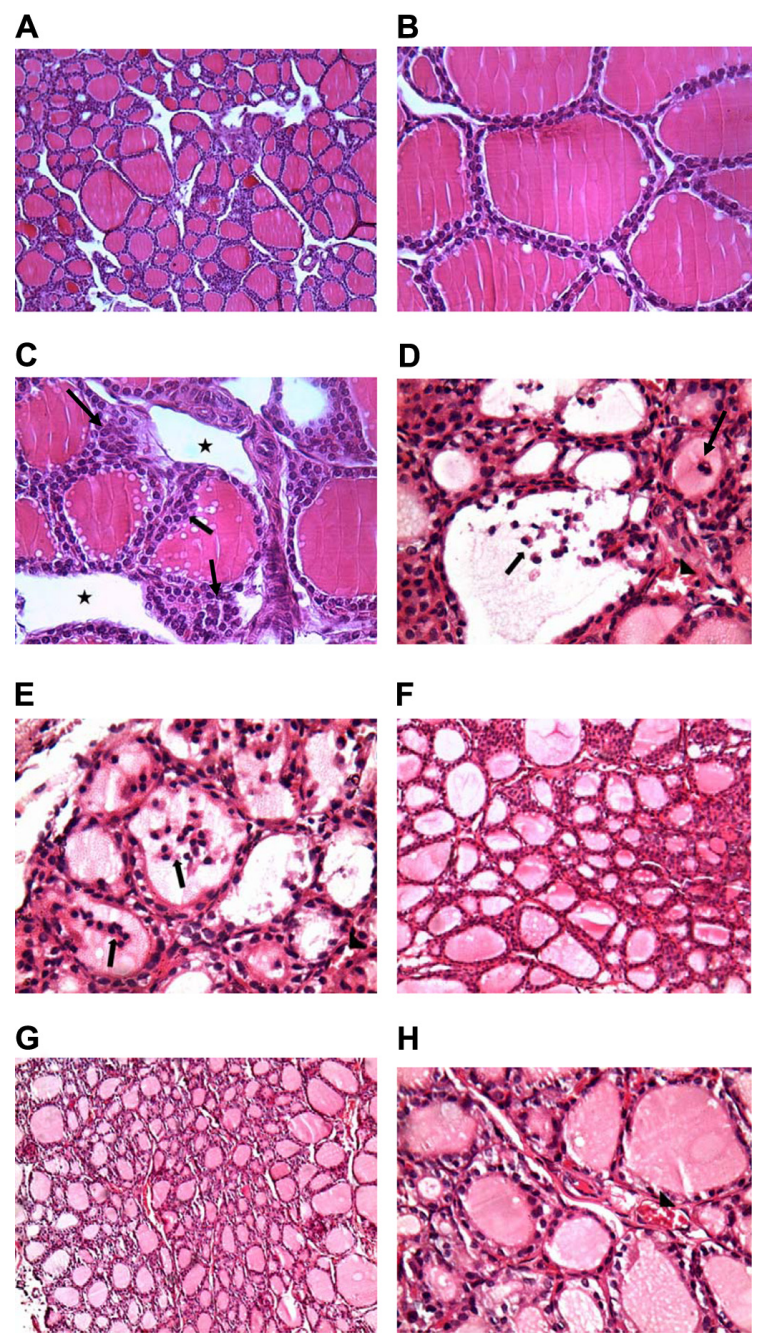

Figure 2 Photomicrographs of (A) thyroids of the control group (group I) at low magnification, showing normal, evenly spaced follicles (H\&E, IOX); (B) thyroids of the control group (group I) at high magnification, showing follicular epithelial cells (H\&E, 40x); (C) thyroids of the chromium-treated group (group 2), showing follicular hyperplasia (arrow) with large interfollicular spaces (star); (D and E) thyroids of the chromium-treated group (group 2), showing desquamated follicles (arrow) and congested interfollicular blood vessels (arrowheads) (H\&E, 40X); (F) thyroids of nano-selenium-treated group (group 3), showing normal follicles; ( $\mathbf{G}$ and $\mathbf{H}$ ) thyroids of nano-selenium chromium-treated group (group 4).

Notes: Sections show near-normal follicular structure, large and small follicles, lightly stained colloid, and reduction of interfollicular spaces. Congested blood capillaries are still present (arrowheads) (H\&E, 10× and 20×, respectively).

Abbreviation: H\&E, hematoxylin and eosin.

This was indicated by significant decreases of free $T_{3}$ and $\mathrm{T}_{4}$ compared to control group (Table 1). These results are similar to results obtained by other scientists who reported that $\mathrm{Cr}(\mathrm{VI})$ induced hypothyroidism and thyroid tissue insult in rats. ${ }^{24}$

$\mathrm{Cr}(\mathrm{VI})$ induced thyroid toxicity through increasing cellular oxidative stress and decreasing the activity of antioxidants. ${ }^{31}$ Our results showed that administration of $\mathrm{Cr}(\mathrm{VI})$ caused a significant decrease in GSH concentration and a significant increase in MDA concentration. These findings 

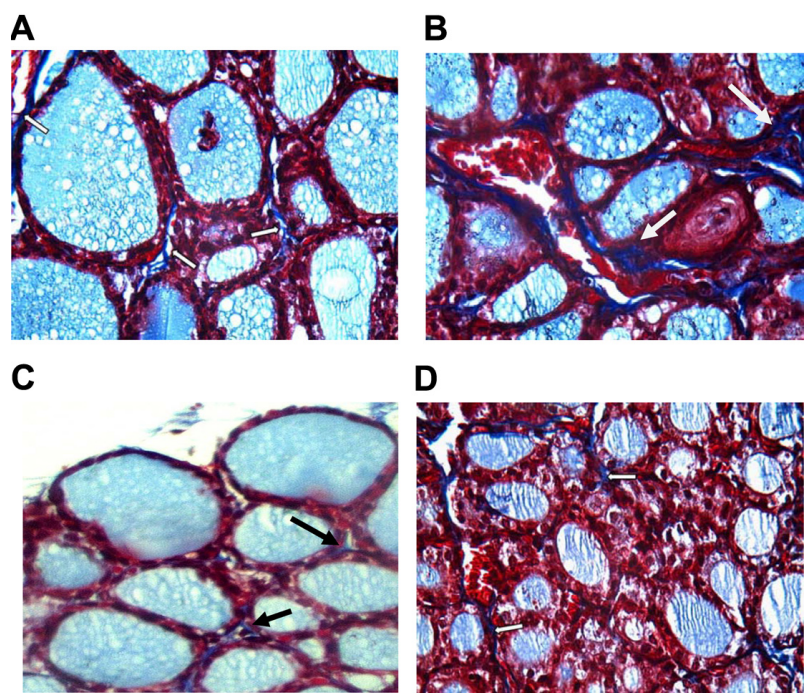

Figure 3 (A-D) Comparison of collagen deposition in thyroids of control and treated rats at high magnification power (Masson's trichrome, 40×).

Notes: (A) In thyroids of group I, collagen (arrow) is minimally present within the gland. (B) In thyroids of group 2, collagen deposition (arrow) increased compared with those of group I. Group 3 (C) and group 4 (D) showed little collagen deposition compared to thyroids of group 2 , as they nearly returned to normal.

are in agreement with the results of many other scientists who have reported that administration of $\mathrm{Cr}(\mathrm{VI})$ causes a significant decrease of GSH contents in rats, ${ }^{31}$ and an increase of catalase and SOD activities compared to the control group (Table 2) in a recent study demonstrated that catalase is a classical oxidative biomarker and is the most abundant in peroxisomes, where oxidative stress most frequently occurs. ${ }^{32}$

A

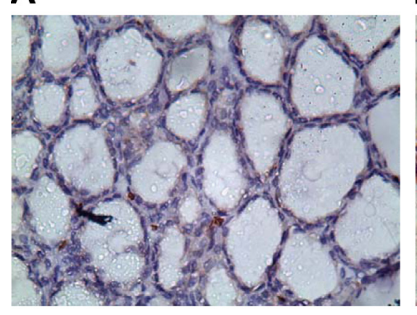

C

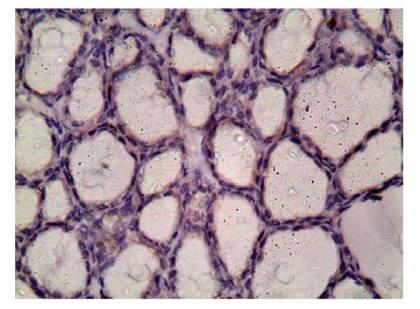

Figure 4 (A-D) Ki67 staining in thyroid tissues at high magnification power (40x). Notes: (A) Thyroids of group I exhibited weak proliferation, as shown by Ki67-positive nuclei. (B) thyroids of group 2 showed strong positive nuclear immunostaining. Thyroids of group 3 (C) and group 4 (D) showed weak positive nuclear immunostaining.
The increase in these enzyme activities suggests a response toward increased ROS generation. ${ }^{33,34}$ Moreover, it is reported that $\mathrm{Cr}(\mathrm{VI})$ often generates free radicals, which in turn activate $\mathrm{O}_{2}$ and produce ROS, including hydroxyl radicals, singlet oxygen, superoxide and hydrogen peroxide, ${ }^{23,35}$ and consequently lead to DNA damage. ${ }^{36}$

In our results, the biochemical alterations were confirmed by the presence of pathomorphological alterations in thyroid glands of rats exposed to $\mathrm{K}_{2} \mathrm{Cr}_{2} \mathrm{O}_{7}$. These alterations are represented by follicular hyperplasia with large interfollicular spaces, desquamated follicles, and congested interfollicular blood vessels (Table 3 and Figure 2). Similar changes in the thyroid tissues following exposure to $\mathrm{K}_{2} \mathrm{Cr}_{2} \mathrm{O}_{7}$ were documented in earlier studies. ${ }^{37}$ Follicular hyperplasia may be connected with a cascade of cellular events involving oxidative stress, genomic DNA damage, and modulation of apoptotic regulatory gene $\left(P^{53}\right)$ after exposure to chromium. ${ }^{21}$ In addition, thyroid glands of rats exposed to $\mathrm{K}_{2} \mathrm{Cr}_{2} \mathrm{O}_{7}$ showed a significant deposition of collagen compared to control rats (Table 3 and Figure 3), and a strongly stained nuclei Ki67 compared to the control group (Table 3 and Figure 4).

The alterations observed in thyroids, including hyperplasia of the intrafollicular epithelium, follicular segregation with increased interfollicular spaces, and desquamated irregular reduced colloidal space, indicate the highly toxic effects of $\mathrm{Cr}(\mathrm{VI})$.

Se nanoparticles have recently come to be known to have antioxidant effects. These effects are declared to be through increasing activities of both GPX and glutathione $S$-transferase-as well as causing less oxidative stress. ${ }^{12,13}$

Treatment of rats with nano-selenium $(3-20 \mathrm{~nm}$ ) (Figure 1) before and after $\mathrm{Cr}(\mathrm{VI})$ exposure appeared to

Table 3 Morphometrical parameters of the thyroid glands of the four tested groups

\begin{tabular}{lllll}
\hline $\begin{array}{l}\text { Morphometrical } \\
\text { parameters }\end{array}$ & Groups & & & \\
\cline { 2 - 5 } & Group I & Group 2 & Group 3 & Group 4 \\
\hline $\begin{array}{l}\text { Follicular } \\
\text { epithelial } \\
\text { cell height }\end{array}$ & $4.86 \pm 0.21$ & $8.97 \pm 0.27^{*}$ & $4.83 \pm 0.31$ & $5.59 \pm 0.49$ \\
$\begin{array}{l}\text { Area percentage } \\
\text { of trichrome- }\end{array}$ & $0.4 \pm 0.5$ & $4.8 \pm 2.5^{*}$ & $0.4 \pm 0.9$ & $0.5 \pm 0.8$ \\
$\begin{array}{l}\text { stained collagen } \\
\text { Area percentage } \\
\text { of ki67-positive } \\
\text { nuclei }\end{array}$ & $0.1 \pm 0.4$ & $2.3 \pm 2.5^{*}$ & $0.3 \pm 0.4$ & $0.6 \pm 0.7$ \\
\hline
\end{tabular}

Notes: Values are expressed as means \pm standard error of mean. *Significant variation at $P<0.05$. 
counter to the hypothyroid status. This was indicated by restoring serum free $T_{3}$ and $T_{4}$ concentrations (Table 1), as well as thyroid antioxidant activity by returning the GSH, MDA concentration, catalase and SOD activities to nearly normal levels (Table 2).

Nano-selenium succeeded in restoring thyroid integrity by lowering oxidative stress, as the administration of Se nanoparticles caused a significant increase in hepatic antioxidant activities (GSH and GR and GST) and depletion of MDA level. ${ }^{38}$ The most important metabolic roles of selenium in mammalian cell are due to its function in the active site of many antioxidant enzymes; like thioredoxin reductase, glutathione peroxidase and glutathione reductase. ${ }^{39}$

Our study suggests that selenium nanoparticles whose size ranges between 3 and $20 \mathrm{~nm}$ may represent a novel therapeutic regenerative material that scavenges ROS caused by exogenously elevated ROS due to $\mathrm{Cr}$ (VI) exposure. When ROS are produced at high levels, cellular components are damaged. These ROS can positively affect biological systems as a defense mechanism against microorganisms. They can also act as signal-transduction and transcription agents in the development of stress responses, and programmed cell death. However, excessive oxidative stress arising from the strong cellular oxidizing potential of excess ROS or free radicals has widespread adverse effects on multiple organ systems, including hepatocellular damage, increased risk of cataracts, cardiovascular disease, and cancer. Recent studies suggest that selenoenzymes, including GTH and thioredoxin, reductase play a role in enhancing the ability of Se to protect against cancer. ${ }^{40}$

Earlier studies demonstrated that elemental Se at nanosize has a comparable efficacy to selenite in upregulating selenoenzymes and tissue Se levels, but it is less toxic. ${ }^{11,41}$ These results challenged the long-held dogma that elemental Se has no biological activity.

In rats receiving both selenium nanoparticles and $\mathrm{K}_{2} \mathrm{Cr}_{2} \mathrm{O}_{7}$, there were no histopathological changes observed in thyroid tissues, as we detected no follicular hyperplasia, or desquamated follicles; in addition, we noticed the absence of interfollicular congestion (Figure 2). Added to that, the rats' thyroids showed little collagen deposition (Figure 3) and less stained nuclei with Ki67 (Figure 4).

The results obtained in this study correlate with earlier studies concerning the influence of different antioxidants on the same organ. The studies showed a stronger preventive action of selenium on the morphological picture of the thyroid. ${ }^{42,43}$ Administration of selenium nanoparticles to rats inhibited the development of changes observed in thyroids after exposure to $\mathrm{K}_{2} \mathrm{Cr}_{2} \mathrm{O}_{7}$.

The present result is the first report on cellular thyroid toxicity induced by $\mathrm{Cr}(\mathrm{VI})$ and amelioration of this damage by administration of nano-selenium. Although few data are available concerning the use of antioxidant against $\mathrm{Cr}(\mathrm{VI})$-induced thyroid toxicity, the result of the use of nano-selenium against toxicity of one of the heavy metals appears to be promising.

\section{Conclusion}

The administration of selenium nanoparticles demonstrated beneficial effects upon biochemical and pathomorphological alterations, developed in thyroids following exposure to $\mathrm{K}_{2} \mathrm{Cr}_{2} \mathrm{O}_{7}$. This proves that nanoparticles play a significant role in chromium toxicity. It could be concluded that the administration of antioxidants in response to an increased risk of exposure to chromium compounds may protect the human body against their harmful effects. Although selenium nanoparticles were able to restore cell structure and/or prevent cellular damage, further frequent detailed investigations using different doses of both hexavalent chromium and selenium nanoparticles are required.

\section{Disclosure}

The authors report no conflicts of interest in this work.

\section{References}

1. Oberdörster G, Oberdörster E, Oberdörster J. Nanotoxicology: an emerging discipline evolving from studies of ultrafine particles. Environ Health Perspect. 2005;113(7):823-839.

2. Nel A, Xia T, Mädler L, Li N. Toxic potential of materials at the nanolevel. Science. 2006;311(5761):622-627.

3. Berzelius JJ. Letter from Mr Berzelius to Mr Berthollet on two new metals. Ann Phys (Paris). 1818;7:199-206. French.

4. Flohé L, Andreesen JR, Brigelius-Flohé R, Maiorino M, Ursini F. Selenium, the element of the moon, in life on earth. IUBMB Life. 2000; 49(5):411-420.

5. Kryukov GV, Gladyshev VN. Mammalian selenoprotein gene signature: identification and functional analysis of selenoprotein genes using biotransformatic methods. Methods Enzymol. 2002;347:84-100.

6. Rayman MP. The importance of selenium to human health. Lancet 2000; 356(9225):233-241.

7. Finley JW. Bioavailability of selenium from foods. Nutr Rev. 2006;64(3): $146-151$.

8. Rayman MP, Infante HG, Sargent M. Food-chain selenium and human health: spotlight on speciation. Br J Nutr. 2008;100(2):238-253.

9. Schrauzer GN. The nutritional significance, metabolism and toxicology of selenomethionine. Adv Food Nutr Res. 2003;47:73-112.

10. Köhrle J, Gärtner R. Selenium and thyroid. Best Pract Res Clin Endocrinol Metab. 2009;23(6):815-827.

11. Zhang J, Wang H, Yan X, Zhang L. Comparison of short-term toxicity between Nano-Se and selenite in mice. Life Sci. 2005;76(10) 1099-1109. 
12. Peng D, Zhang J, Liu Q, Taylor EW. Size effect of selenium nanoparticles (Nano-Se) at supranutritional levels on selenium accumulation and glutathione S-transferase activity. J Inorg Biochem. 2007;101(10): 1457-1463.

13. Zhang J, Zhang SY, Xu, JJ, Chen HY. A new method for the synthesis of selenium nanoparticles and the application to construction of $\mathrm{H}_{2} \mathrm{O}_{2}$ biosensor. Chin Chem Lett. 2004;15(11):1345-1348.

14. Gao X, Zhang J, Zhang L. Hollow sphere selenium nanoparticles: their in-vitro anti-hydroxyl radical effect. Adv Mater. 2002;14(4):290-293.

15. Wang $\mathrm{H}$, Zhang J, Yu H. Elemental selenium at nano size possesses lower toxicity without compromising the fundamental effect on selenoenzymes: comparison with selenomethionine in mice. Free Radic Biol Med. 2007;42(10):1524-1533.

16. Shin Y, Blackwood JM, Bae IT, Arey BW, Exarhos GJ. Synthesis and stabilization of selenium nanoparticles on cellulose nanocrystal. Mater Lett. 2007;61:4297-4300.

17. Porter D, Raymond LW, Anastasio GD. Chromium: friend or foe? Arch Fam Med. 1999;8(5):386-390.

18. Kawanishi S, Hiraku Y, Murata M, Oikawa S. The role of metals in site-specific DNA damage with reference to carcinogenesis. Free Radic Biol Med. 2002;32(9):822-832.

19. He X, Lin GX, Chen MG, Zhang JX, Ma Q. Protection against chromium (VI)-induced oxidative stress and apoptosis by Nrf2. Recruiting Nrf2 into the nucleus and disrupting the nuclear Nrf2/Keap1 association. Toxicol Sci. 2007;98(1):298-309.

20. Barceloux D. Chromium. Clin Toxicol. 1999;37(2):173-194.

21. Bagchi D, Stohs SJ, Downs BW, Bagchi M, Preuss HG. Cytotoxicity and oxidative mechanisms of different forms of chromium. Toxicology. 2002;180(1):5-22.

22. Levina A, Codd R, Dillon CT, Lay PA. Chromium in biology: toxicology and nutritional aspects. Prog Inorg Chem. 2003;51:145-250.

23. Ye J, Wang S, Leonard SS, et al. Role of reactive oxygen species and p53 in chromium(VI)-induced apoptosis. J Biol Chem. 1999;274(49): 34974-34980.

24. Qureshi IZ, Mahmood T. Prospective role of ascorbic acid (vitamin C) in attenuating hexavalent chromium-induced functional and cellular damage in rat thyroid. Toxicol Ind Health. 2010;26(6):349-359.

25. Beutler E, Duron O, Kelly MB. Improved method for determination of blood glutathione. J Clin Med. 1963;61:882-888.

26. Aebi HE. Catalase: In: Bergmeyer HU, editor. Methods of Enzymatic Analysis. Hoboken (NJ); 1984;273-286.

27. Nishikimi M, Roa NA, Yogi K. The occurrence of superoxide anion in the reaction of reduced phenazine methosulfate and molecular oxygen. Biochem Biophys Res Commun. 1972;46(2):849-854.

28. Satoh K. Serum lipid peroxide in cerebrovascular disorders determined by a new colorimetric method. Clin Chem Acta. 1978;90(1): 37-43.

29. Ohkawa H, Ohishi W, Yogi K. Assay for lipid peroxides in animal tissues by thiobarbituric acid reaction. Anal Biochem. 1979;95(2):351-358.
30. Maartens LH, Erasmus BJ, Clift SJ. Tissue tropism of African horsesickness virus in the chicken embryo demonstrated with the avidin-biotin complex immunoperoxidase method. Vet Pathol. 2011;48(6): 1085-1093.

31. Thompson CM, Proctor DM, Haws LC, et al. Investigation of the mode of action underlying the tumorigenic response induced in B6C3F1 mice exposed orally to hexavalent chromium. Toxicol Sci. 2011;123(1):58-70.

32. Bocchetti R, Regoli F. Seasonal variability of oxidative biomarkers, lysosomal parameters, metallothioneins and peroxisomal enzymes in the Mediterranean mussel Mytilus galloprovincialis from Adriatic Sea. Chemosphere. 2006;65(6):913-921.

33. Kyle ME, Miccadei S, Nakae D, Farber JL. Superoxide dismutase and catalase protect cultured hepatocytes from the cytotoxicity of acetaminophen. Biochem Biophys Res Commun. 1987;149(3): 889-896.

34. Amin KA, Mohamed SH, El-Said TA, Khalid SH. The protective effects of cerium oxide nanoparticles against hepatic oxidative damage induced by monocrotaline. Int J Nanomedicine. 2011;6:143-149.

35. Aiyar J, Berkovits HJ, Floyd RA, Wetterhahn KE. Reaction of chromium(VI) with glutathione or with hydrogen peroxide: identification of reactive intermediates and their role in chromium(VI)induced DNA damage. Environ Health Perspect. 1991;92:53-62.

36. Zhang XH, Zhang X, Wang XC, et al. Chronic occupational exposure to hexavalent chromium causes DNA damage in electroplating workers. BMC Public Health. 2011;11:224.

37. Mahmood T, Qureshi IZ, Iqabi MJ. Histopathological and biochemical changes in rat thyroid following acute exposure to hexavalent chromium. Histol Histopathol. 2010;25(11):1355-1370.

38. Liguang S, Xuna W, Yuea W, et al. Effect of sodium selenite, Se-yeast and nano-elemental selenium on growth performance, Se concentration and antioxidant status in growing male goats. Small Rumin Res. 2011;96(1):49-52.

39. Flora SJ, Kannan GM, Pant BP, Jaiswal DK. Combined administration of oxalic acid, succimer and its analogue for the reversal of gallium arsenide induced oxidative stress in rats. Arch Toxicol. 2002;76(5-6):269-276.

40. Irons R, Carlson BA, Hatfield DL, Davis CD. Both selenoproteins and low molecular weight selenocompounds reduce colon cancer risk in mice with genetically impaired selenoprotein expression. J Nutr. 2006;136(5):1311-1317.

41. Zhang JS, Gao XY, Zhang LD, Bao YP. Biological effects of a nano red elemental selenium. Biofactors. 2001;15(1):27-38.

42. Brzezińska-Slebodzińska E. Fever induced oxidative stress: the effect on thyroid status and the 5 '-monodeiodinase activity, protective role of selenium and vitamin E. Physiol Pharmacol. 2001;52(2):275-284.

43. Demelash A, Karlsson JO, Nilsson M, Björkman U. Selenium has a protective role in caspase-3-dependent apoptosis induced by $\mathrm{H}_{2} \mathrm{O}_{2}$ in primary cultured pig thyrocytes. Eur J Endocrinol. 2004;150(6): 841-849.
International Journal of Nanomedicine

\section{Publish your work in this journal}

The International Journal of Nanomedicine is an international, peerreviewed journal focusing on the application of nanotechnology in diagnostics, therapeutics, and drug delivery systems throughout the biomedical field. This journal is indexed on PubMed Central, MedLine, CAS, SciSearch ${ }^{\circledR}$, Current Contents ${ }^{\circledR} /$ Clinical Medicine,

\section{Dovepress}

Journal Citation Reports/Science Edition, EMBase, Scopus and the Elsevier Bibliographic databases. The manuscript management system is completely online and includes a very quick and fair peer-review system, which is all easy to use. Visit http://www.dovepress.com/ testimonials.php to read real quotes from published authors. 